\title{
Adsorption and Desorption of CO on W(110) Surfaces
}

\author{
Taek-seung Yang, Hae-geun Jee, Jin-Hyo Boo, Hyun Seok Han, Gyung Hee Lee, Young Dok Kim, and Soon-Bo Lee
}

\author{
Department of Chemistry, Sunghunkwan Unversin, Suwon. Gveonggi $140-7+6$. Korea

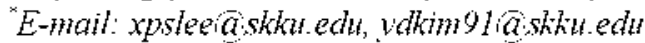 \\ Received Februarv 23,2008
}

\begin{abstract}
The adsorption of CO on W(110) surfaces was studied using thermal desorption spectroscopy (TDS). and core and valence level spectroscopy. At $120 \mathrm{~K}$, CO forms a tilted structure at lower coverages $\left(\alpha_{1}\right)$, whereas it adsorbs normal to the surface at higher coverages $\left(\alpha \alpha_{2}\right)$. Tilted structures have been suggested to be precursors of dissociative chemisorption: however, experimental evidence is provided for the non-dissociative chemisorption of $\mathrm{CO}$ at temperatures above $900 \mathrm{~K}$ (which is referred to as the $\beta$-state): TDS shows first order desorption kinetics. The core and valence level spectra of $\mathrm{O} / \mathrm{W}(110)$ and those of $\beta-\mathrm{CO} / \mathrm{W}(110)$ are different. Most importantly, the $4 \sigma$ molecular orbital of $\mathrm{CO}$ can be identified in the valence level spectra of the $\beta$-CO.
\end{abstract}

Key Words : Tungsten. CO. Chemisorption. Photoelectron spectroscopy

\section{Introduction}

Information on the chemisorption of small gas molecules on transition metal surfaces is crucial to obtain a molecularlevel understanding of the mechanism of heterogeneous catalysis and. thus, chemisorption on single crystal surfaces has been extensively studied in the past in surface chemistry and ply sics. In the case of $\mathrm{CO}$ on transition metal surfaces. which is one of the most extensively studied systems in surface chenistry due to its technological importance as well as its structural simplicity, a transition from dissociative to molecular chemisorption has been found in traversing from the left to the right side of the periodic table. ${ }^{1} \mathrm{~W}$ lies at the borderline between the molecular and dissociative chemisorption of $\mathrm{CO}$, and it is a long-standing question as to whether $\mathrm{CO}$ is dissociated or not on $\mathrm{W}$ surfaces.

In the late 1950s, Elrlich and coworkers found that no residual carbon or oxygen remained on $\mathrm{W}$ after repeated cycles of adsorption of $\mathrm{CO}$ and subsequent heating to 2300 $\mathrm{K}$. It was concluded that $\mathrm{CO}$ is non-dissociatively bound to W surfaces. ${ }^{2}$ A similar conclusion was drawn by Gomer and others, who used thermal desorption spectroscopy (TDS) and field ionization microscopy (FIM). ${ }^{3.6}$

In later studies, however, several experimental works suggested the dissociative chenisorption of $\mathrm{CO}$ on $\mathrm{W}$ surfaces. Goymour and King observed the second order desorption of $\mathrm{CO}$ at around $1500 \mathrm{~K}$, and the dissociative chenisorption of $\mathrm{CO}$ was suggested. ${ }^{7 \cdot 5}$ The chenisorption state below $600 \mathrm{~K}$ was assigned to molecular chemisorption, whereas the highertemperature-state (which is called the $\beta$-state) to dissociative chemisorption. Wang et al. also used TDS to study CO chemisorption on $\mathrm{W}(100)$. concluding that $\mathrm{CO}$ is dissociatively adsorbed in the $\beta$-state. ${ }^{1 j}$ Umbach et al. used photoelectron spectroscopy, suggesting dissociative chenisorption of $\mathrm{CO}$ in the $\beta$-state. ${ }^{11,12}$ In the works of Unbach et al. transition from virgin- to dissociated-CO was proposed to take place at around room temperature. ${ }^{11,12}$ In the recent literature, the dissociative chemisorption of $\mathrm{CO}$ on W surfaces has been more generally proposed than nondissociative adsorption based on experimental and theoretical results. ${ }^{13.17}$

Spectroscopic determination of the structure of $\mathrm{CO}$ in the $\beta$-state is non-trivial: for example, using vibrational spectroscopy, the absence of the $\mathrm{C}-\mathrm{O}$ stretching mode can be attributed to its dissociative chemisorption: however. according to the surface selection rule. a lying down species with a $C$. $O$ bond axis parallel to the surface may not be active. ${ }^{16}$ In the valence band spectra, the $4 \sigma$ state of $\mathrm{CO}$ cannot be found due to its very low cross section in the lying-down structure. The $5 \sigma$ and $\mathrm{I} \pi$ states of $\mathrm{CO}$ cannot be clearly discriminated from the $\mathrm{O} 2 \mathrm{p}$ state.

In contrast to these previous works, we found some evidence for the non-dissociative chemisorption of $\beta$ - $\mathrm{CO}$ on W(111) surfaces using TDS in combination with photoelectron spectroscopy ${ }^{18.19}$ Using the atomic superposition and electron delocalization molecular orbital (ASED-MO) method, the non-dissociative chemisorption of $\mathrm{CO}$ on W(111), (110) and (100) surfaces was proposed ${ }^{? 01,21}$ In the present work. CO chemisorption on W(110) surfaces was studied experimentally. In particular, synchrotron radiation was used to obtain higher quality valence band spectra. We found evidence for the molecular chemisorption of $\beta$ - $\mathrm{CO}$ at temperatures above $900 \mathrm{~K}$, which is quite in contrast to earlier reports.

\section{Experimental}

The experiments were performed in an ultrahigh vacuum (UHV) system with a base pressure of $1 \times 10^{-15}$ torr equipped for x-ray photoelectron spectroscopy (XPS), low energy electron diffraction (LEED) and quadrupole mass spectrometry (QMS).

The $W(110)$ samples were cleaned by thermal treatment at $1700 \mathrm{~K}$ under an $\mathrm{O}_{2}$ atmosphere of $2 \times 10^{-8}$ torr, and subsequent heating to $2300 \mathrm{~K}$. This procedure was repeated until no impurities could be found using LEED and XPS 
The sample temperature was measured using a C-type thermocouple spot-welded on its side. For the TDS experiments. a heating rate of $6 \mathrm{~K} / \mathrm{s}$ was used. which was controlled using a programmed integral differential (PID) controller. The sample was cooled using a He-cryogenic sy stem. which was connected to the sample using a $\mathrm{Cu}$ wire. For $\mathrm{CO}$ chemisorption, the UHV chamber was backfilled with $\mathrm{CO}$.

The $\mathrm{O}$ ls and valence band spectra were collected in the Polhang Accelerator Laboratory (beam line 2Bl). For the photoenission experiments in Pohang. the analyzer was placed normal to the sample surface, and the angle between the synchrotron radiation and the analyzer aperture was $45^{\circ}$. The sample temperature was measured by a pyrometer in Polnang.

\section{Results and Discussion}

TDS results. Figure I shows the TDS spectra collected after exposing the clean $W(110)$ surface to various amounts of $\mathrm{CO}$ at room temperature. Three distinct features can be observed at $\sim 400,-1000$ and $-1150 \mathrm{~K}$. which are denoted as

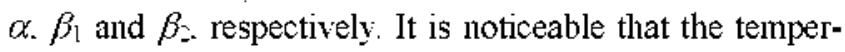
atures corresponding to the maximum desorption rate for the $\alpha$ and $\beta_{\text {s }}$ states are almost constant for a given anount of $\mathrm{CO}$ exposure. When the $\mathrm{CO}$ exposure exceeds $1.5 \mathrm{~L}$ (Langmuir $=$ torr $\times \mathrm{sec}$.). an additional state at $1000 \mathrm{~K}\left(\beta_{1}\right)$ appears.

Considering the previous data in the literature. it is reasonable to suggest that the $\alpha$-state corresponds to the molecular $\mathrm{CO}$ species adsorbed perpendicular to the surface. with the carbon atom directly attached to the $\mathrm{W}$ surface. ${ }^{17.19}$ Gomer et al. and Umbach et al. used the term "virgin- $\mathrm{CO}^{*}$ for the low-temperature species. which is dented as $\alpha-\mathrm{CO}$ in the present work. $^{6.11 .12}$

As mentioned in the introduction. the structure of $\beta-\mathrm{CO}$ is still under debate: either molecular or dissociative cheni-

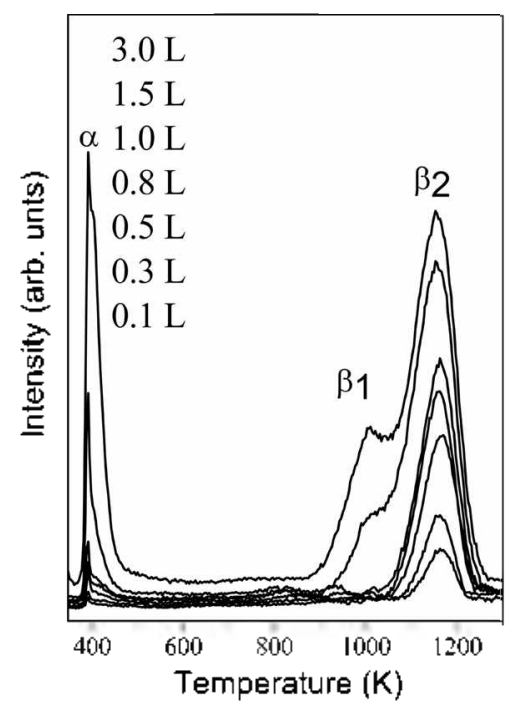

Figure 1. Thernal Desortion Spectra of co obtained after exposing W(110) to varions amounts of $\mathrm{CO}$ at room temperature. The heating rate was $6 \mathrm{~K} / \mathrm{s}$.

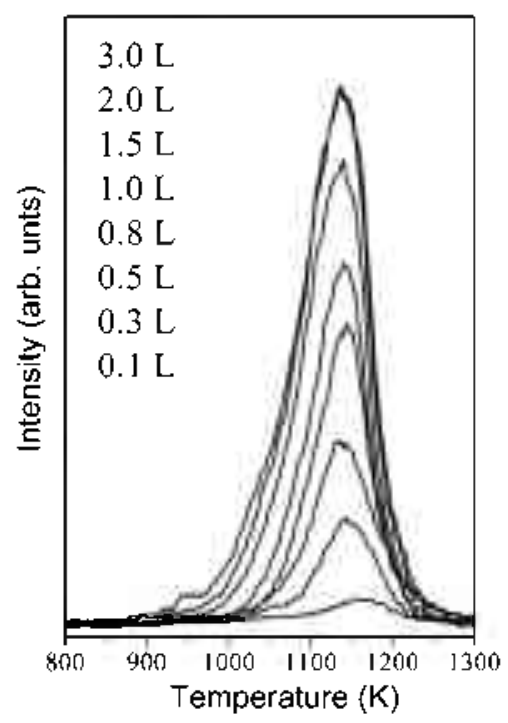

Figure 2. Thenmal Desorption Spectra of CO obtained after exposing $\mathrm{W}(110)$ to various amounts of $\mathrm{CO}$ at $900 \mathrm{~K}$. The heating rate was $6 \mathrm{~K} / \mathrm{s}$.

sorption has been suggested in the past. Figure 2 shows the TDS spectra of $\mathrm{CO}$ obtained after $\mathrm{CO}$ exposures at $900 \mathrm{~K}$, at which only the $\beta_{2}$ state forms. Our TDS spectra are more suggestive of the molecular chemisorption of $\mathrm{CO}$ in the $\beta_{2}$ $\mathrm{CO}$ : for the dissociative chemisorption of $\mathrm{CO}$, the recombination of $\mathrm{C}$ and $\mathrm{O}$ should precede $\mathrm{CO}$ desorption, i.e. the desorption of $\mathrm{CO}$ is described by second order kinetics. In this case, the shape of the TDS spectra should be symmetric and the temperature corresponding to the maximum desorption rate should gradually shift toward the lower temperature range with increasing $\mathrm{CO}$ coverage. ${ }^{21}$ In contrast. for first order desorption (molecular chemisorption of $\mathrm{CO}$ ). the temperature corresponding to the maximum desorption rate should be constant as a function of the amount of $\mathrm{CO}$ exposure, and an asymmetric peak shape should be obser:ed. ${ }^{2-}$ The asymmetric shape of the desorption peak of the $\beta_{-}$ $\mathrm{CO}$ state suggests first order desorption kinetics. i.e. $\mathrm{CO}$ is molecularly chemisorbed in this state. There is a small peak shift as a function of the $\mathrm{CO}$ exposure. yet the coverage dependent shift of this peak can be rationalized by the existence of repulsive lateral interactions between adsorbates. $^{23}$

It is, however, important to mention that one should scrutinize for drawing a conclusion about the adsorption structure CO only based on TDS data. Later, we will show that photoelectron spectroscopy can provide more clear evidence on the adsorption structure of the $\beta_{2}-\mathrm{CO}$.

XPS results-core level spectra. Figure 3 shows the $O$ ls spectrum obtained after exposing the $W(110)$ surface to 5.0 $\mathrm{L}$ of $\mathrm{CO}$ at room temperature (spectrum a). In addition, the $\mathrm{O}$ ls spectra of the $\beta_{\text {r-state with different coverages are }}$ compared. These specimens were prepared by exposing the W(110) surface to various amounts of $\mathrm{CO}$. followed by subsequent heating to $900 \mathrm{~K}$ (b-d). For the surface exposed to $5.0 \mathrm{~L}$ of $\mathrm{CO}$ at room temperature. an $\mathrm{O} 1 \mathrm{ls}$ state centered at $529.9 \mathrm{eV}$ with a shoulder at $\sim 531-532 \mathrm{eV}$ can be found. 


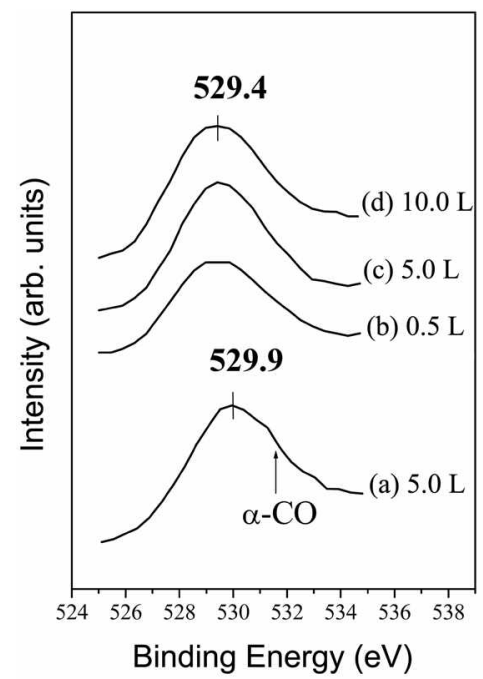

Figure 3. (a) $O$ ls spectra after exposing $W(110)$ to $5.0 \mathrm{~L}$ of $\mathrm{CO}$ at roon temperature. Synchrotron radiation with a photon energy of $770 \mathrm{eV}$ was used. (b-d) After $\mathrm{CO}$ exposure at room temperature, the samples were heated to $900 \mathrm{~K}$ and then the $\mathrm{O}$ is spectra were collected. The $\mathrm{CO}$ doses are given in the figure.

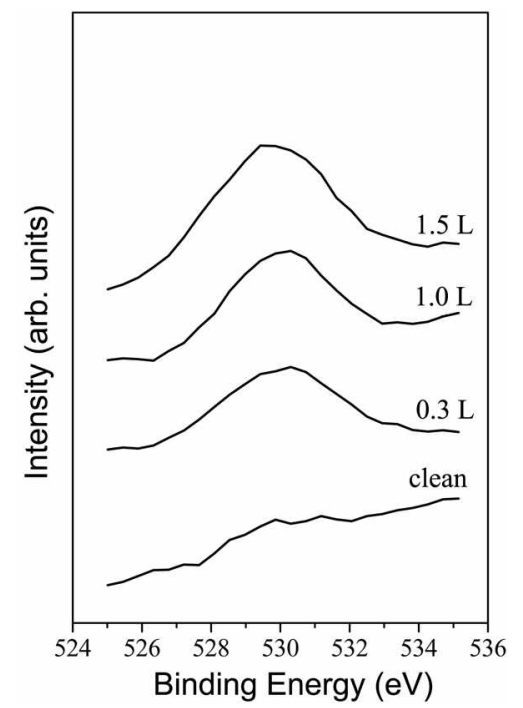

Figure 4. $\mathrm{O}$ Is spectra taken after exposing $\mathrm{W}(110)$ to various amounts of $\mathrm{O}_{2}$, followed by heating to $1500 \mathrm{~K}$. A photon energy of $770 \mathrm{eV}$ was used.

whereas the $\beta_{2}$-state shows a peak at $529.4 \mathrm{eV}$ (Fig. 3).

For the sake of comparison, the $O$ ls spectra were collected from W(110) surfaces exposed to various amounts of oxygen and subsequently flashed to $1500 \mathrm{~K}$. A comparison of the $\mathrm{O}$ 1s spectrum of the $\beta_{-}-\mathrm{CO}$ and that of oxygen can reveal whether $\mathrm{CO}$ is dissociated or not. As a function oxygen exposure. the $\mathrm{O}$ 1s binding energy changes within $0.2 \mathrm{eV}$ (Fig. 4). Assuming that $\mathrm{CO}$ is dissociatively chemisorbed the $\mathrm{O}$ is spectrum of $\mathrm{CO}$ and that of oxy'gen on $W(110)$ should be identical. The $O$ ls binding energies of Figure 4 are significantly different from that of the $\beta_{2}-\mathrm{CO}$ in Figure 3. suggesting that $\mathrm{CO}$ is non-dissociatively chemisorbed in the $\beta_{2}$-state.

In general. the binding energy of the $\mathrm{O}$ Is level of mole-

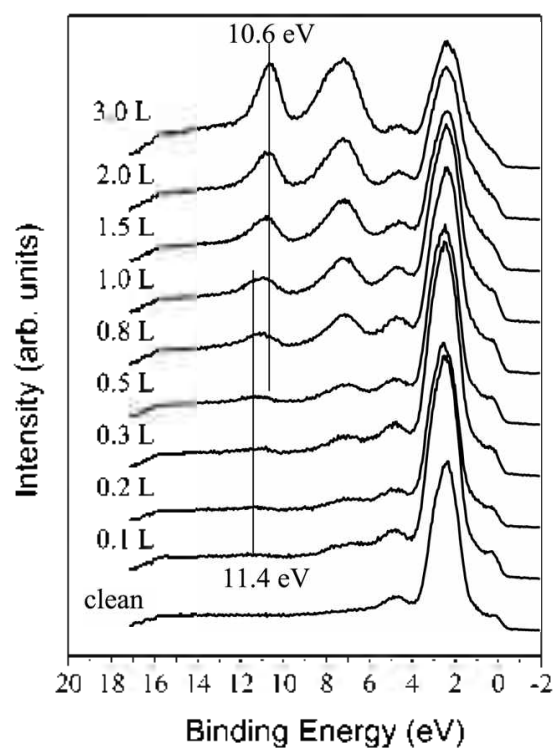

Figure 5. Valence band spectra obtained after exposing $W(110)$ to various amounts of $\mathrm{CO}$ at $120 \mathrm{~K}$. A photon energy of $90 \mathrm{eV}$ was used.

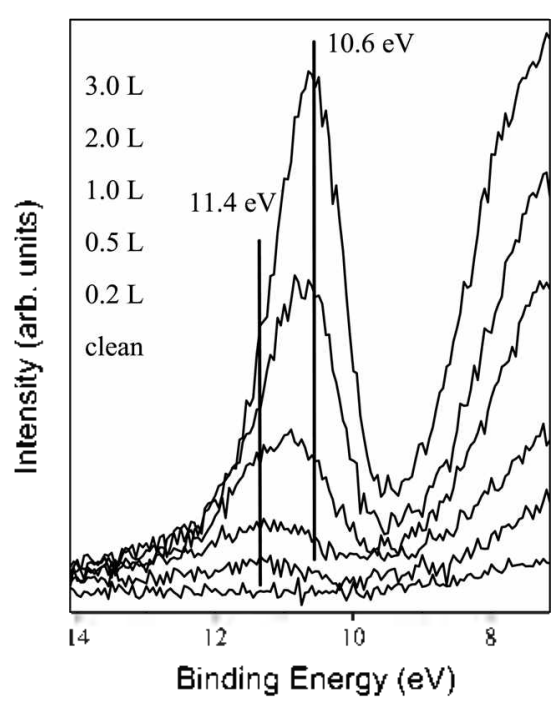

Figure 6. A magnified view of some spectra in Fig. 5 is shown in order to clearly see the evolution of the $4 \sigma$ state as a function of CO exposure.

cularly bound $\mathrm{CO}$ is centered at $\sim 532 \mathrm{eV}^{11}$ The $\mathrm{O}$ ls binging energy of the $\beta$-CO state in the present work is $529.4 \mathrm{eV}$, which is much lower. In the next section. we will show that the $\beta$-CO is most likely a lying-down species, in which the $\pi$ bond is broken. In this case, the chemical environments of oxygen in the $\beta$-CO should be much different from those of upright $\mathrm{CO}$ species. resulting in large core $(\mathrm{O}$ Is) level sluft between the $\alpha$ - and the $\beta$-CO.

Valence band spectra. In Figures 5 and 6 , the valence band spectra are shown. which were obtained after exposing the $\mathrm{W}(110)$ surface to various amounts of $\mathrm{CO}$ at $120 \mathrm{~K}$. At lower $\mathrm{CO}$ exposures. new $\mathrm{CO}$-derived features appear at 7.0 $\mathrm{eV}$ and $11.4 \mathrm{eV}$ below the Fenmi level. As the $\mathrm{CO}$ exposure becomes larger. the peak at $7.0 \mathrm{eV}$ becomes asymmetric. 

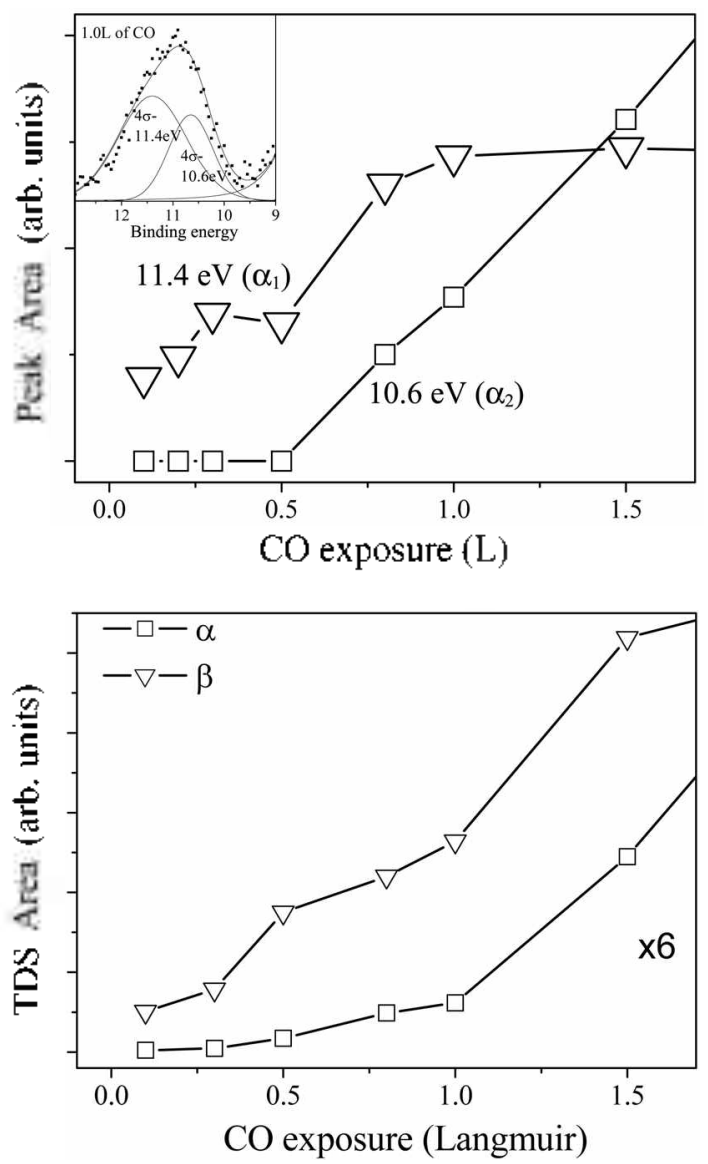

Figure 7. Top: Each spectrum in Fig. 5 was fitted by tour Gaussian functions, two of them for the $1 \pi+5 \sigma$ state, and the other two for the $4 \sigma$ state, and the relative intensity ratios of the two different $4 \sigma$ states are summarized. In the inset, a magnified view of a fitted valence band spectrum is shown as a representative example, which was taken after a $\mathrm{CO}$ exposure of $1.0 \mathrm{~L}$. Bottom: the relative intensity ratios of the $\alpha$ - and $\beta$-CO in the TDS spectra in Fig. 1 are summarized.

The peak at $11.4 \mathrm{eV}$ saturates in intensity at a $\mathrm{CO}$ exposure of $0.8 \mathrm{~L}$. At even larger $\mathrm{CO}$ exposures. an additional shoulder appears at $10.6 \mathrm{eV}$. Signals below $5 \mathrm{eV}$ correspond to the metallic d-states of $\mathrm{W}$.

Based on the previous results. the peak at a binding energy of $7.0 \mathrm{eV}$ can be assigned to the overlap of the $5 \sigma$ and $1 \pi$ orbitals of $\mathrm{CO}$. whereas the feature at about $\mathrm{ll} \mathrm{eV}$ is ascribed to the $4 \sigma$ orbital. This assignment is supported by previous calculations of the photoionization cross sections as well as angle-resolved ultraviolet photoelectron spectroscopy. $2+20$

Detailed analysis of the $4 \sigma$ states in Figures 5 and 6 suggests that there are at least two different adsorption structures of $\mathrm{CO}$ at $120 \mathrm{~K}$. The $4 \sigma$ state of each spectrum was fitted by two different Gaussian functions centered at $11.4\left(\alpha_{1}\right)$ and $10.6 \mathrm{eV}\left(\alpha_{2}\right)$, and the results are summarized in Figure 7. ${ }^{3 i j .31}$ As mentioned above, it can be seen that the peak at $11.4 \mathrm{eV}$ rapidly grows at the initial stage of $\mathrm{CO}$ exposure and saturates at a $\mathrm{CO}$ exposure of $0.8 \mathrm{~L}$. whereas the $10.6 \mathrm{eV}$-peak grows after the saturation of the $\alpha_{1}$-state.

For comparison, the variation of the relative TDS peak areas of the different states is summarized in Figure 7. At lower $\mathrm{CO}$ coverages, the â-state is selectively occupied, and the $\alpha$-peak starts to grow when the $\mathrm{CO}$ exposure exceeds 1 L. This result is in line with the previous data of Gomer et $a l^{6}$ The $\mathrm{CO}$ exposure dependent belhavior of the $\beta$-state in the TDS spectra is quite analogous to that of the $\alpha_{1}$-peak in the valence band spectra. whereas the $\alpha$-peak in the TDS spectra to that of the $\alpha_{2}$-peak in the valence band spectra. This result is in line with the previous data of Gomer $e t \mathrm{al}^{6}$ This result suggests that the $\alpha_{2}$-state at $120 \mathrm{~K}$ desorbs at $-400 \mathrm{~K}$ (the $\alpha$-state in TDS). whereas the $\alpha_{1}$-state desorbs at temperatures above $900 \mathrm{~K}$ (the $\beta$-state in TDS). Based on the previous results obtained for the chemisorption of $\mathrm{CO}$ on $\mathrm{Cr}(110)$ and $\mathrm{Fe}(100)$ surfaces, the following adsorption mechanism of $\mathrm{CO}$ can be suggested: at $120 \mathrm{~K}$. $\mathrm{CO}$ adsorbs with a tilted geometry at lower $\mathrm{CO}$ coverages $\left(\alpha_{1}\right){ }^{3 i j-32} \mathrm{After}$ the saturation of the $\alpha_{1}$-state. additional $\mathrm{CO}$ adsorbs with an upright structure ( $\alpha_{2}$-state). Upon heating, the $\mathrm{CO}$ molecules with an upright geometry desorb at $-400 \mathrm{~K}$. whereas the tilted CO molecules desorb at temperatures above $900 \mathrm{~K}$.

Previously, a similar experimental result to ours was obtained using high-resolution electron energy loss spectroscopy (HREELS). ${ }^{16}$ In this previous work, the tilted state was preferentially occupied at lower $\mathrm{CO}$ coverages $<<0.5$ $\mathrm{ML}$ ). and the upright structure was formed after the tilted state had become nearly saturated at $90 \mathrm{~K}$. The tilted and upright structures could be clearly identified by their C-O stretching frequencies of 1360 and $2000 \mathrm{~cm}^{-1}$. respectively. ${ }^{16}$

In the TDS spectra, it is evident that the number of $\mathrm{CO}$ molecules in the $\alpha$-state is lower than that in the $\beta$-state. However. the intensity of the $4 \sigma$ orbital peak of the $\alpha_{2}$-state at $10.6 \mathrm{eV}$ is much higher than that of the $\alpha_{1}$-state $(11.4 \mathrm{eV})$. In a previous study of $\mathrm{CO}$ chemisorption on $\mathrm{Fe}(100)$ surfaces using HREELS in combination with ultraviolet photoelectron spectroscopy (UPS), the decrease of the $4 \sigma /$ $(5 \sigma+1 \pi)$ ratio upon heating was attributed to the gradual change of the adsorption structure from a vertical to a tilted geometry. ${ }^{32}$ This is in line with our suggestion that the $\alpha_{1}$ state corresponds to the tilted geometry of $\mathrm{CO}$. whereas the $\alpha_{2}$-state corresponds to the upright structure. Based on TDS results. one can estimated the relative amount of $\alpha_{1}$ - and $\alpha_{2}$ $\mathrm{CO}$. By combining this infomation with the UPS results. one can roughly calculate the ratio of the photoemission cross sections of the $4 \sigma$ orbital of the $\alpha_{1}$ - and the $\alpha_{2}-\mathrm{CO}$. We estimate that the photoemission cross section of the to of the $\alpha_{1}$-state is larger than that of the $\alpha_{2}-\mathrm{CO}$ by roughly two orders of magnitudes. In the tilted geometry, the $4 \sigma$ orbital should be more stable due to the stronger chemical bond between $\mathrm{W}$ and $\mathrm{CO}$, and therefore the binding energy of the $4 \sigma$ orbital of the tilted $\mathrm{CO}$ should be higher that that of the upright structure. ${ }^{31.331 .33}$ In our results. the binding energy of the $4 \sigma$ orbital of $\alpha_{1}-\mathrm{CO}$ is indeed higher than that of $\alpha_{3}-\mathrm{CO}$.

In order to shed light on the structures of the various chemisorption states of $\mathrm{CO}$ on $\mathrm{W}(110)$, valence band spectra were taken after exposing the surface to $3.0 \mathrm{~L}$ of $\mathrm{CO}$ at 120 $\mathrm{K}$ followed by stepwise heating (Fig. 8). Upon heating, the $\mathrm{CO}$-derived features gradually decrease in intensity due to 


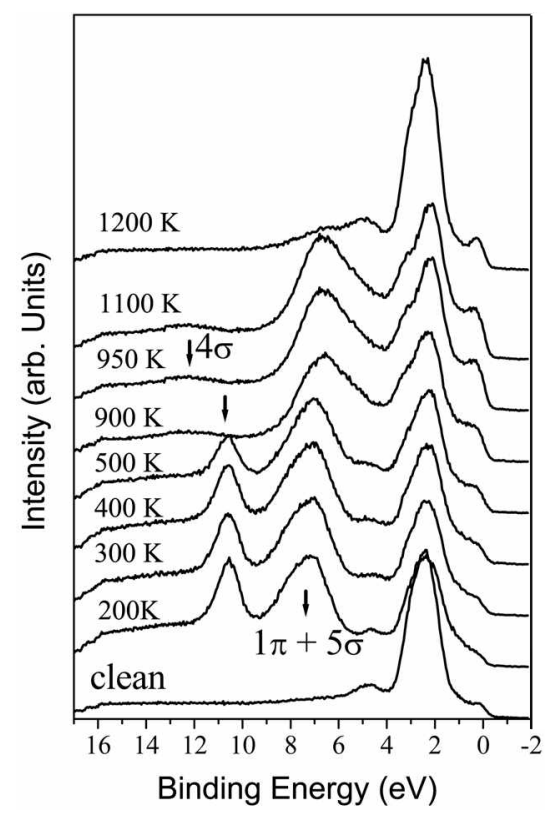

Figure 8. W(110) was exposed to $3.0 \mathrm{~L}$ of $\mathrm{CO}$ at $120 \mathrm{~K}$ and the valence band spectra were collected after stepwise heating. The heating temperature for each spectrum is given in the figure.

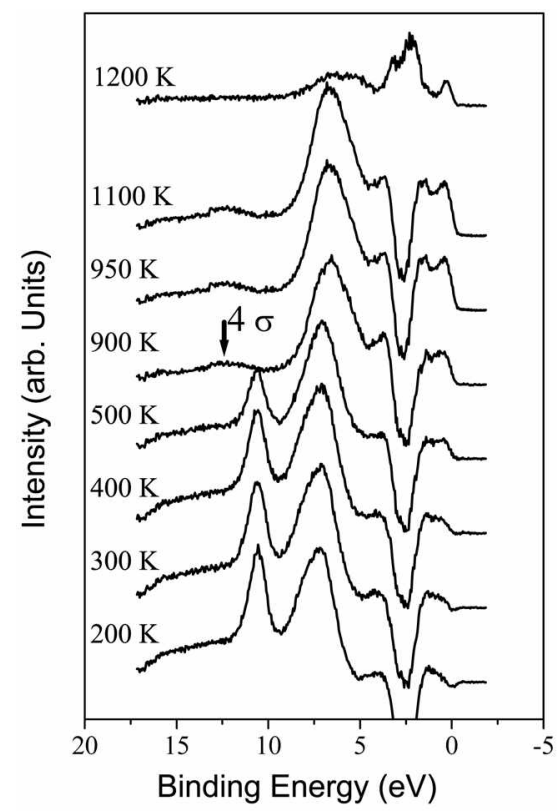

Figure 9. The clean surface spectrun was subtracted from each spectrum in Fig. 7 (difference spectrum). The heating temperature of each spectrum is denoted in the.

the desorption of $\mathrm{CO}$. It is important to note that the relative intensity of the $4 \sigma$ peak with respect to that of the $(5 \sigma+1 \pi)$ state becomes smaller with increasing heating temperature. As mentioned above. a smaller $4 \sigma$ peak intensity was found for the tilted geometry of $\mathrm{CO}$ compared to that of the upright structure i.e. upon tilting the cross section of the $4 \sigma$ state for the photoelectron emission becomes smaller. The vertically adsorbed $\mathrm{CO}$ on $\mathrm{W}(110)$ desorbs first at lower temperatures. leaving only the tilted species above $500 \mathrm{~K}$. Most importantly, the $\mathrm{CO}$-derived $4 \sigma$ feature is still observable

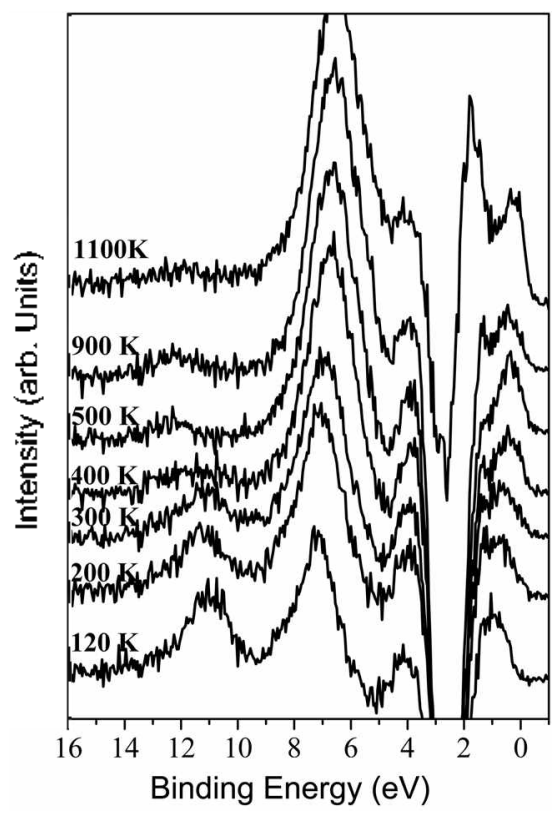

Figure 10. Difference spectra of valence band spectra collected after exposing $W(110)$ to $0.8 \mathrm{~L}$ of $\mathrm{CO}$ at $120 \mathrm{~K}$ followed by stepwise heating. The heating temperature of each spectrum is given in the figure.

after heating the sample to $900 \mathrm{~K}$. indicating the molecular chemisorption of $\mathrm{CO}$ rather than dissociative chemisorption in the $\beta_{z}$-state. The existence of the CO-derived features above $900 \mathrm{~K}$ can be more clearly observed in the difference spectra (Fig. 9). When the initial CO exposure was changed from $3.0 \mathrm{~L}$ to $0.8 \mathrm{~L}$ (Fig. 10), the valence band spectra showed similar results to those of Figures 8 and 9. Upon heating at temperatures above $900 \mathrm{~K}$, the $4 \sigma$ peak is shifted to a higher binding energy. whereas the $(5 \sigma+1 \pi)$ peak shifted to a lower binding energy, resulting in an increase in the separation between the $4 \sigma$ and $(5 \sigma+1 \pi)$ peaks (Fig. 810). Compared to the binding energy of the $4 \sigma$ state of the $\alpha_{1}-\mathrm{CO}$ at $120 \mathrm{~K}$, heat treatment at $900 \mathrm{~K}$ increases the binding energy of the $4 \sigma$ state, implying that upon heating there is a structural transition of the $\alpha_{1}-\mathrm{CO}$ from a less to a more stable structure, i.e. $\mathrm{CO}$ is tilted in the $\alpha_{1}$-state at 120 $\mathrm{K}$ and. upon heating to higher temperatures. it tilts more and more, finally becoming a lying-down species. The $4 \sigma$ peak of the $\beta_{2}=$ state is centered at $12.5 \mathrm{eV}$, which is shifted by 2 $\mathrm{eV}$ with respect to the $\alpha-\mathrm{CO}$. Theoretical calculations predict a positive shift of the $4 \sigma$ state. as the upright structure becomes a lying down species: however, the experimentally observed shift is larger than the theoretically predicted values. which are below $1 \mathrm{eV}^{\text {?1,23 }}$

The valence band spectra clearly show that $\mathrm{CO}$ adsorption on $\mathrm{W}(110)$ at $120 \mathrm{~K}$ results in two different adsorption structures with vertical and tilted geometries. The tilted species is occupied first and the vertical ones later. On $\mathrm{Cr}(110)$ surfaces. a similar result was found for $\mathrm{CO}$ adsorption at $100 \mathrm{~K}$ : CO first adsorbs with a tilted (or ly ing down) geometry, and then the vertical $\mathrm{CO}$ is formed after the saturation of the tilted $\mathrm{CO}{ }^{3 i, 31} \mathrm{~A}$ sumilar phenomenon was found on $\mathrm{Fe}(100)$ surfaces ${ }^{32}$ There is, however. a major 


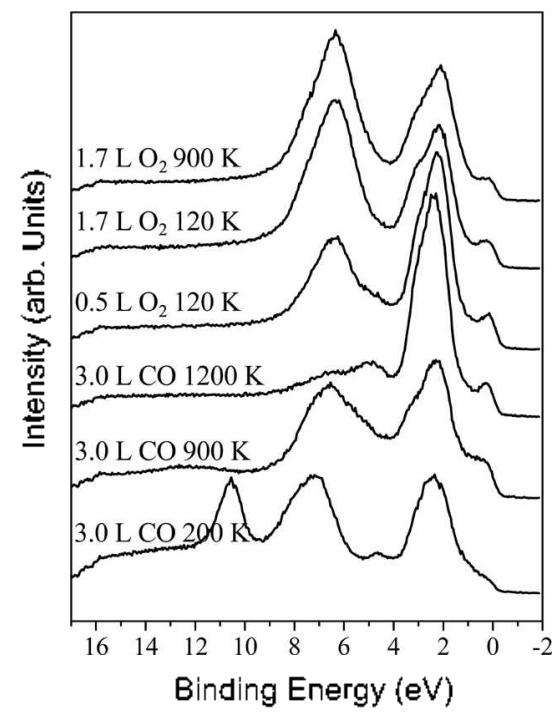

Figure 11. Valence band spectra collected after exposing $W(110)$ to various amounts of $\mathrm{CO}$ and $\mathrm{O}_{2}$ at difterent temperatures. The details of the gas exposure and temperature are given in the figure.

difference between $\mathrm{Cr}(110), \mathrm{Fe}(100)$ and $\mathrm{W}(110)$ regarding their $\mathrm{CO}$ chemisorption behaviors: the tilted species was found to be a precursor state of $\mathrm{CO}$ dissociation on $\operatorname{Cr}(110)$ and $\mathrm{Fe}(100)$ : however. on $\mathrm{W}(110)$ surfaces, we show that the tilted species does not dissociate upon heating. ${ }^{3(1.3 \hat{3}}$

Previously. the $\mathrm{C}-\mathrm{O}$ stretching frequency could not be detected upon heating the $\mathrm{CO}$ pre-covered $\mathrm{W}(110)$ surfaces above $250 \mathrm{~K}$ and. thus. dissociation of the intramolecular bond of $\mathrm{CO}$ upon heating was suggested..$^{10} \mathrm{It}$ is, however. important to note that. based on the surface selection rule. the detection of the $\mathrm{C}-\mathrm{O}$ bond of a lying-down species using HREELS under specular conditions is impossible. and. thus. the absence of the C-O stretching frequency in the HREELS spectrum does not necessarily indicate the dissociative chemisorption of $\mathrm{CO}$.

For comparison. a W(110) surface was exposed to various amounts of oxygen and the valence band spectra were collected (Fig. 11). An oxygen-induced state at $6.4 \mathrm{eV}$ can be observed without any additional peak above $10 \mathrm{eV}$, which is apparently different from the results of the $\beta-\mathrm{CO}$, again suggesting that the structure of the $\beta-\mathrm{CO}$ cannot be explained by dissociative chemisorption, but only by molecular chemisorption.

\section{Conclusion}

At $120 \mathrm{~K}$. we could identify two different $\mathrm{CO}$ adsorption states. which we attribute to the tilted $\left(\alpha_{1}\right)$ and upright $\left(\alpha_{2}\right)$ structures, respectively. The tilted $\mathrm{CO}$ was previously suggested to be a precursor of the dissociated state; however. we show that the tilted $\mathrm{CO}$ maintains its $\mathrm{C}-\mathrm{O}$ bond until its desorption takes place. The following experimental data of the $\beta_{z}$-state (desorbing at $\sim 1150 \mathrm{~K}$ ) support the nondissociative chemisorption of $\mathrm{CO}$ on W(110) surfaces: TDS shows first order desorption kinetics and XPS shows different $\mathrm{O}$ ls binding energies of $\mathrm{CO}$ from those of oxygen atoms chemisorbed on the same surface. In the valence band spectra. molecular chemisorption can be identified by the state at $\sim 1 \mathrm{l} \mathrm{eV}$ below the Fermi level. which is assigned to the $4 \sigma$ orbital of $\mathrm{CO}$.

Acknowledgements. This work was supported by the SRC program (CNNC) of MOST/KOSEF (grant Rll-2001$091-00000-0$ ). Support of the research by the BK 21 project of Ministry of Education. Korea. is gratefully acknowledged. The experiments at PLS were supported in part by MOST and POSTC and Dr. Ki-jeong Kim and Dr. Bongsoo Kim are acknowledged for their support in PLS.

\section{References}

1. Horn. K: Bradshaw. A.: Tacobi. K. Surf. Sci. 1978. 72.719.

2. Ehrlich. G.: Hichmott. I. W.: Hudda. F. G. J. Chem. Phes 1958. 28.506 .

3. Ehrlich, G. d. Chem. Plys. 1961. 34. 39.

4. Swanson. L. W.: Gomer, R J. Chem. Phys. 1963, 39. 2813.

5. Klein. R. J. Chem. Phus. 1959, 31.1306.

6. Kohrt. C.: Gomer. R. Surf. Sci. 1973. +0.71.

7. Goymour. C. G.: King. D. A. J. Chem. Soc. Foraday Trans. I 1973. 69.736

8. Goymour. C. G.; King, D. A. J. Chem. Soc. Faraday Trans. 1 1973. 69,749

9. Goymour. C. G.: King. D. A. Swf. Sci. 1973. 35, 246.

10. Wang. C.: Gomer. R. Surf. Sci. 1979. 90. 10.

11. Umbach. E.: Fuggle. T. C.: Menzel. D. J. Electron Sipec and Rel. Phenont 1977. 10.15.

12. Umbach. E.: Menzel. D. Surf. Sci. 1983. 135, 199

13. Yates. Jr. J. T. Swf. Sci. 1994, 299,731

14. Campuzano, J. C. The Adsorption of Carbon Honoxide by Transition Metals; The Chemical Plnsics of Solid Surfaces and Heterogeneous Catahlsis: King. D. A.: Woodruff. D. P.. Eds.: Elservier: Amsterdam. 1990: Vol. 3. Part A3.

15. Shimizhu. Y:; Ohi. A.: Tokumoto. H. Swf. Sci. 1999, +29, 143.

16. Houston. J. E. Surf. Sci. 1991. 255.303.

17. Chen. L.: Sholl, D. S.: Johnson. J. K. J. Plns. Chem. B 2006, 110. 1344.

18. Lee. S. Y.: Kim. Y.-D.: Yang. T. S.: Boo. J-H.: Park. S. C.: Lee. S.-B. J. Vac. Sci. Technol A 2000. 18. 1455.

19. Lee. S. Y: Kim, Y. D.: Seo, S. N.; Park. C. Y.: Kwak, H. T:, Boo. J.-H.: Lee. S.-B. Bull. Kor: Chem. Soc. 1999, 20. 1061.

20. Ryu. G. H.: Park. S. C.: Lee, S.-B. Surf. Sci. 1999, 427-428. 419

21. Choe. S. T.: Kang. H. J.: Park. D. H.: Huh. D. S.: Lee. S.-B. bull. kor. Chem. Soc. 2004. 25. 1314

22. Introduction to Surface Physical Chemismy. Christmann. K.. Ed.: Springer: New York, 1991.

23. Principles of Adsoiption and Reaction on Solid Surfaces, Masel. R. I.. Ed.; John Wiley and Sons, Inc:: 1996.

24. Eastmant. D. E.: Cashion. K. Phys. Rev. Lett 1971. 27. 1520.

25. Fuggle J. C.: Steinkillerg. M.: Metzel. D. Chem. Phys. 1975. 1 . 307 .

26. Allyn. C. L.: Gustatsson, T; Plummer. E. W. Sold State Comm 1977. 24, 531 .

27. Davenport, J. W. Plys. Rev Lett. 1976. $36,945$.

28. Stnith. R. I.: Andersont. J. A.: Lepeyre. G. I. Phws. Rev. Lett. 1976. 37. 1081 .

29. Apai. G.: Wehner. P. S.: Williams. R. S.: Stohr. J.: Shirley. D. A Phys. Rev Lett. 1976, 37.1497

30. Shinn. N. D.: Madey. T. E. Phus, Rev B 1986, 33 . 1464.

31. Shinn. N. D. Phys. Rev B 1988, $38,12248$.

32. Benndort. C.: Nieber. B.: Kruger. B. Sinf. Sci. 1986. 177. L907.

33. Mehandru. S. P.: Anderson. P. Sinf. Sci. 1988. 201. 345. 